\title{
PROTECTIVE EFFECT OF CUMIN (CUMINUM CYMINUM L.) SEED EXTRACT ON CARDIOVASCULAR SYSTEM, TOXICITY, AND HEMATOLOGY ON HYPERLIPIDEMIC RABBITS: AN EXPERIMENTAL STUDY
}

\author{
HARSHLATA CHOUHAN*, ASHOK PUROHIT
}

Department of Zoology, Jai Narayan Vyas University, Jodhpur, Rajasthan, India. Email: harshlata.chouhan@gmail.com Received: 18 May 2018, Revised and Accepted: 22 June 2018

\section{ABSTRACT}

Objective: The present study is related with the assessment of anti-atherosclerotic efficacy of $70 \%$ EtOH extract of cumin seed in diet-induced hyperlipidemic rabbits.

Methods: Rabbits were rendered hyperlipidemic by oral administration of cholesterol for 15 days. Then, the animals were treated with $70 \% \mathrm{EtOH}$ (ethanolic extract) of cumin seed extract for 45 days (Group III). Another set of animals was treated with atorvastatin, the standard drug for 45 days. At the end of experimental period, the serum biochemical, hematological, and histological analysis of thoracic aorta was done.

Results: The cumin seed extract showed contain hypolipidemic effect by reducing plasma cholesterol, low-density lipoproteins, and triglycerides level. While toxicological studies suggest no adverse effect on renal and liver function tests, hematological parameters were also observed in a normal range. Histological analysis showed that cholesterol administration caused a narrowing of the aortal lumen while treatment with $70 \%$ EtOH and atorvastatin decreased the plaque size and restored the luminal size of the aorta to normal.

Conclusion: The present study suggests that commonly used culinary spice cumin seed possesses hypolipidemic and cardioprotective effect with a positive effect on serum biochemistry, histology, and hematology.

Keywords: Atherosclerosis, Hyperlipidemia, Cumin seed, Cardioprotective.

(c) 2018 The Authors. Published by Innovare Academic Sciences Pvt Ltd. This is an open access article under the CC BY license (http://creativecommons. org/licenses/by/4. 0/) DOI: http://dx.doi.org/10.22159/ajpcr.2018.v11i10.27400

\section{INTRODUCTION}

Atherosclerosis underlies the leading reason of mortality and morbidity globally. Initiation of atherosclerosis involves a decade-long expansion of the arterial intima, which occurs due to an intricate interaction of circulatory factors and various cell types in the vessel wall including endothelial cells, lymphocytes, monocytes, and smooth muscle cells [1]. Cardiovascular disease (CVD) causes 1 of every 5 deaths in past years [2]. Current allopathic drug treatment for atherosclerosis involves statin (HMG-Co-A reductase inhibitors), fibrates, niacin, and bile acid resins. Among these remedies, the statin is the most widely and reliably used drug as it directly lowers the serum cholesterol level by competitively inhibiting HMG-CoA reductase enzyme in the liver [3]. However, as the main end product of HMG-CoA activity is mevalonate, which acts as a precursor of many other non-steroidal isoprenoid compounds, so the inhibition of this enzyme results in pleiotropic effects and thus long-term consumption of statin causes several side effects [4]. Side effects of statin are labeled as statinassociated symptoms which include muscular damage (statinassociated muscle symptoms), rarely rhabdomyolysis, statin-induced narcotizing myopathy, diabetes mellitus, Alzheimer's, and dementia [5]. If the condition of atherosclerosis goes more severe, the patients are suggested to undergo cardiovascular surgery. Cardiovascular surgery is an important treatment [6], but these surgical alternatives are very expensive. Hence, there is a need to find an effective, reliable drug with less or none side effects and the answer relies on herbal medicines. Studies suggest that 4 billion people (about $80 \%$ population) prefer herbal medicines for some aspects of primary health care [7]. Dietary plants and their ingredients can act effectively for the management of hyperlipidemia as they have been reported to possess lipid digestion and absorption inhibiting constituents [8]. In traditional medicinal system, aromatic plants have always been important and being used for a long time [9]. Cuminum cyminum Linn. is one of the important culinary, aromatic plants used as primary medicine for a long time. The present work is focused on exploring the cardioprotective and antiatherosclerotic effect of cumin seed extract on cholesterol-fed rabbits.

\section{METHODS}

Extraction of plant material

Dried and cleaned seeds of the C. cyminum (Linn.) were bought from the local market. $70 \%$ of ethanolic extract was prepared with the use of Soxhlet apparatus for $24 \mathrm{~h}$. The extract was treated under low pressure and temperature and then distilled to remove excess of ethanol from the extract. After complete removal of ethanol from the extract, it was dried to obtain the brown-colored sticky extract. The extract was stored in desiccation for future use in experiments.

\section{Experimental animals}

New Zealand white rabbits weighing between 1 and $1.25 \mathrm{~kg}$ were obtained from the certified institute. Animals were acclimatized for 10 days before the onset of the experiment. Animals were kept in clean, metallic wire gauge cages in a room with 12:12 h light-dark cycle, 20$25^{\circ} \mathrm{C}$ temperature, and $40-50 \%$ relative humidity and were fed with standard pellet diet and fresh green vegetables and drinking water. The experimental protocol was approved by the Institutional Animal Ethical Committee (Reg No.: 1646/GO/Re/12/CPCSEA).

\section{Experimentation}

Induction of hyperlipidemia

Rabbits were rendered hyperlipidemic by the oral dose of cholesterol powder at the dose of $500 \mathrm{mg} / \mathrm{kg}$.b.wt./day dissolved in $5 \mathrm{ml}$ of coconut oil for 15 days. 


\section{Dose regimen of atorvastatin}

Atorvastatin (Atorlip-10, Cipla) was used as a standard hypolipidemic drug. It was orally administrated at the dose of $0.25 \mathrm{mg} / \mathrm{kg} . b . w t . /$ day dissolved in $5 \mathrm{ml}$ of distilled water.

\section{Preparation of plant drug}

$70 \%$ of ethanolic extract $(500 \mathrm{mg} / \mathrm{kg}$ b.wt.) was then given to the experimental animals by mixing it in $5 \mathrm{ml}$ distilled water. The dose of the extract was determined by $\mathrm{LD}_{50}$ test.

\section{Experimental design}

The experimental period was of 60 days and divided into four groups $(n=5)$.

Group I: Intact control

Group II: Hyperlipidemic control

Group III: 70\% EtOH of cumin seed treatment group

Group IV: Atorvastatin (Atorlip-10) treatment group.

\section{Assessment of hematology}

Blood was collected by direct cardiac puncture at the end of experimental period. The collected blood was stored in EDTA vials at $-20^{\circ} \mathrm{C}$. Hematological assessments of hemoglobin, TRBC, hematocrit, mean corpuscular volume, mean cell hemoglobin, mean corpuscular hemoglobin concentration, red cell distribution width, total leukocyte count, platelet count, plateletcrit, mean platelet volume, and platelet distribution width were examined using hematology analyzer through standard methods [10].

\section{Assessment of serum biochemistry}

At the end of experimental period, animals were sacrificed under prolonged anesthesia and direct cardiac puncture. Serum was separated by centrifugation of blood at $3000 \mathrm{rpm}$ for $15 \mathrm{~min}$ and stored at $-20^{\circ} \mathrm{C}$ for further need. Serum samples were analyzed using Biochem Autoanalyzer RX-50 (Microlab Instrument) for total cholesterol (TC), highdensity lipoprotein-cholesterol (HDL-C), and triglycerides (TGs) using commercial diagnostic kits (Siemens Healthcare Diagnostics, USA). Low-density lipoprotein (LDL)-cholesterol and very-LDL (VLDL-C) were calculated by Friedewald's formula [11]. TC/HDL and LDL/HDL were also calculated as ischemic indices to access the atherogenic risk. The toxicity profile was also performed by standard kits [12].

\section{Histopathology of the aorta}

The thoracic aorta was cut (2-3 cm length) and excised from the heart. The tissue was cleaned in $0.9 \%$ saline and kept in $10 \%$ formalin fixative. The processed aorta was then ultrasectioned (5-6 $\mu \mathrm{m}$ thickness). Sectioned tissues were stained with hematoxylin and eosin stain and examined under the light microscope for histopathological observations.

\section{Statistical analysis}

All biochemical parameters were expressed as the mean \pm standard error of the mean. One-way ANOVA was analyzed using Tukey's multiple comparison tests. GraphPad Prism-7 was used for data analysis, and graphical representation was made using MS Excel-2007. Level of significance was expressed as $\mathrm{p}<0.05$.

\section{RESULTS}

\section{Effect on lipid profile}

A drastic increase in serum TC was observed when high cholesterol diet was administered to the animals, and this increase in TC was decreased significantly $85 \%(p \leq 0.01)$ in animals treated with $70 \%$ EtOH of cumin seed extract. While highly significant $(p \leq 0.001)$ increase in HDL-C concentration was observed in the hyperlipidemic group, this level came back down when treated with 70\% EtOH cumin seed extract and statin. Similarly, in the case of LDL-C, 96\%, in VLDL-C, 39.61\%, and in TG, $64.08 \%$ reduction were observed in cumin seed extracttreated groups which are comparable with statin treatment. CHOL/ HDL and HDL/LDL ratio of both $70 \%$ EtOH cumin seed extract and statin-treated groups were comparable with the control group. Total lipid concentration also showed high significant (83.69\%) increase in case of the hyperlipidemic group, while other two groups showed significant decrease, and $74.78 \%$ in cumin extract treated and $81.88 \%$ in atorvastatin-treated groups were observed.

\section{Effect on serum biochemistry}

Serum biochemical analysis suggests that there is a considerable increase in the level of blood sugar in the hyperlipidemic group while cumin seed extract and atorvastatin-treated animals showed almost normal values near to the control group. Some of the other parameters of the liver functional test and the renal function test did not show any considerable variation throughout the experimental period in all the four groups.

\section{Effect on hematology}

Observations suggest that no noticeable variation was observed in hematological parameters. All the parameters were near the control values.

Effect on aortic plaque formation (Figs. 1 and 2, Tables 1 and 2) Histopathological study of ascending aorta shows plaque formation with the presence of foam cells, collagen, and lipid deposition causing thickened intimal lining, resulting in narrowing of the arterial lumen,

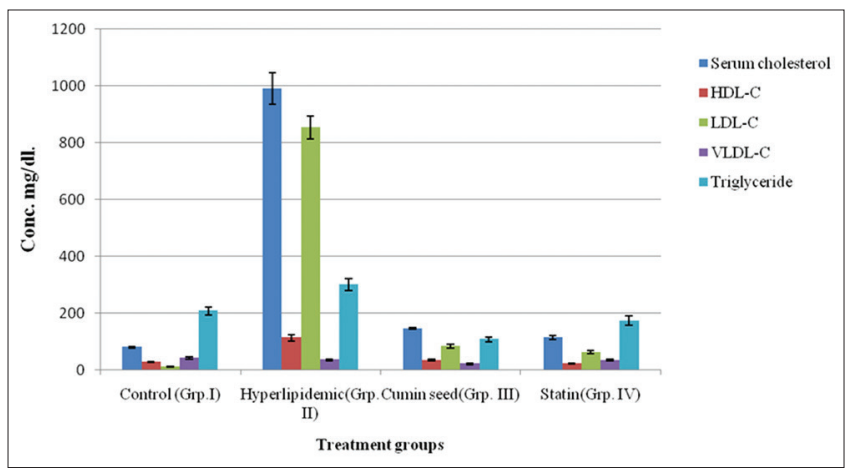

Fig. 1: Graphical representation of the effect of $70 \%$ EtOH extract of cumin seed-treated hyperlipidemic rabbits. (Mean of five values \pm standard error of the mean)

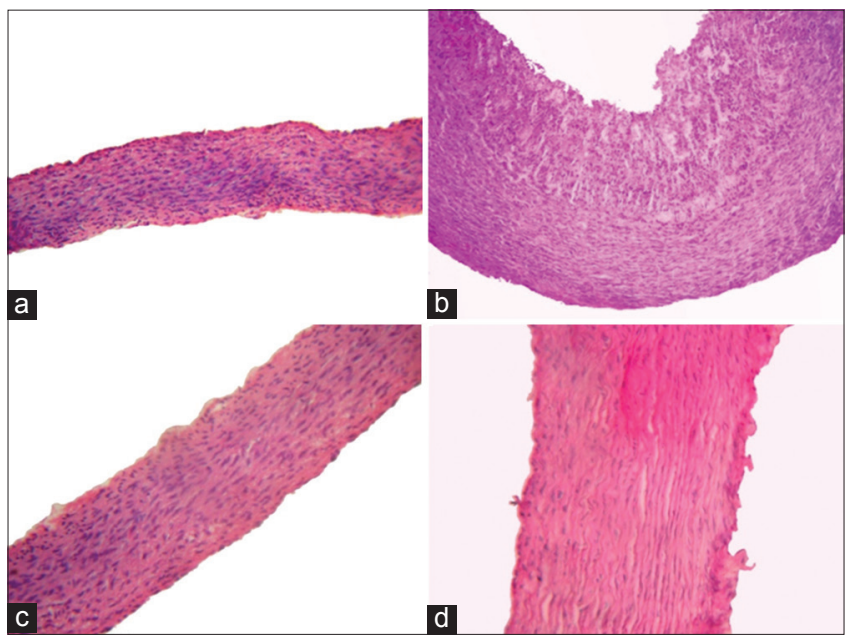

Fig. 2: Photomicrographs (H and E stain, 100x) of thoracic aorta of treated rabbits - (a) intact control: Thoracic aorta showing normal histology with aortic wall consisting of tunica adventitia, tunica media, and tunica intima. (b) Hyperlipidemic: Thoracic aorta exhibiting endothelium with the formation of atherosclerotic plaque which has thickened intima with large number of

foam cells. (c) Cumin extract treated: Aorta showing normal histoarchitecture with restoration in endothelial wall integrity. (d) Atorvastatin: Restored histoarchitecture of thoracic aorta 
Table 1: Serum lipid profile of cholesterol-fed rabbits treated with $70 \%$ EtOH of cumin seed extract

\begin{tabular}{|c|c|c|c|c|c|c|c|c|}
\hline Treatment groups & $\begin{array}{l}\text { TC } \\
\text { (mg/dl) }\end{array}$ & $\begin{array}{l}\text { HDL C } \\
(\mathrm{mg} / \mathrm{dl})\end{array}$ & $\begin{array}{l}\text { LDL-C } \\
\text { (mg/dl) }\end{array}$ & $\begin{array}{l}\text { VLDL-C } \\
\text { (mg/dl) }\end{array}$ & $\begin{array}{l}\text { TG } \\
\text { (mg/dl) }\end{array}$ & TC/HDL & HDL/LDL & $\begin{array}{l}\text { Total lipid } \\
\text { (mg/dl) }\end{array}$ \\
\hline Group I: Intact control & $79.8 \pm 9.63$ & $27.3 \pm 2.01$ & $11.11 \pm 1.36$ & $19.46 \pm 1.67$ & $80.16 \pm 6.01$ & $2.92 \pm 0.31$ & $2.45 \pm 0.2$ & $388.71 \pm 30.16$ \\
\hline $\begin{array}{l}\text { Group II: Hyperlipidemic } \\
\text { control }\end{array}$ & $990.08 \pm 60.16^{c}$ & $112.9 \pm 11.16^{c}$ & $853.6 \pm 71.16^{c}$ & $35.44 \pm 4.76^{b}$ & $299.22 \pm 25.12^{c}$ & $10.63 \pm 1.63^{c}$ & $9.29 \pm 0.87^{c}$ & $2379.8 \pm 210.16^{c}$ \\
\hline $\begin{array}{l}\text { Group III: Cumin seed } \\
\text { extract }\end{array}$ & $145.74 \pm 13.12^{\mathrm{b}, \mathrm{g}}$ & $34.26 \pm 5.01^{\mathrm{d}, \mathrm{g}}$ & $33.3 \pm 2.67^{\mathrm{c}, \mathrm{g}}$ & $21.4 \pm 2.61^{\mathrm{d}, \mathrm{f}}$ & $107.53 \pm 11.23^{\mathrm{a}, \mathrm{g}}$ & $4.2 \pm 0.33^{\mathrm{b}, \mathrm{g}}$ & $2.14 \pm 0.16^{\mathrm{d}, \mathrm{g}}$ & $599.01 \pm 70.12^{\mathrm{c}, \mathrm{g}}$ \\
\hline Group IV: Atorvastatin & $113.35 \pm 9.01^{\mathrm{a}, \mathrm{g}}$ & $27.05 \pm 1.97^{\mathrm{d}, \mathrm{g}}$ & $24.69 \pm 2.06^{\mathrm{c}, \mathrm{g}}$ & $24.6 \pm 2.2^{\mathrm{a}, \mathrm{e}}$ & $173.45 \pm 13.79^{\mathrm{c}, \mathrm{f}}$ & $5.38 \pm 0.42^{\mathrm{c}, \mathrm{f}}$ & $0.33 \pm 0.01^{\text {c.g }}$ & $431.37 \pm 41.12^{\mathrm{d}}$ \\
\hline
\end{tabular}

Values expressed as mean \pm SEM ( $n=5$ ). Groups II to IV compared with Group I, where ${ }^{\mathrm{p} p} \leq 0.05$, ${ }^{\mathrm{b}} \mathrm{p} \leq 0.01$, ${ }^{\mathrm{p} p} \leq 0.001$ and dnon-significant=d. Groups III and IV are compared with Group II, where ${ }^{e} \mathrm{p} \leq 0.05$, fp $\leq 0.01$, gp $\leq 0.001$ and hnon-significant=h. SEM: Standard error of the mean, TC: Total cholesterol, HDL: High-density lipoprotein, LDL: Low-density lipoprotein, VLDL: Very low-density lipoprotein, TGs: Triglycerides

Table 2: Serum biochemistry of cholesterol-fed rabbits treated with $70 \%$ EtOH of cumin seed extract

\begin{tabular}{llll}
\hline Biochemical parameters & $\begin{array}{l}\text { Group I: Intact } \\
\text { control }\end{array}$ & $\begin{array}{l}\text { Group II: Hyperlipidemic } \\
\text { control. }\end{array}$ & $\begin{array}{l}\text { Group III: Cumin seed } \\
\text { extract }\end{array}$ \\
\hline Blood sugar (mg/dl) & $89.5 \pm 8.76$ & $118.4 \pm 15.12^{\mathrm{a}}$ & $\begin{array}{l}\text { Group } \\
\text { IV: Atorvastatin }\end{array}$ \\
Blood urea (mg/dl) & $46.05 \pm 3.66$ & $82.3 \pm 8.76^{\mathrm{b}}$ & $95.2 \pm 8.9^{\mathrm{d}, \mathrm{h}}$ \\
Creatinine (mg/dl) & $0.81 \pm 0.07$ & $1.25 \pm 0.16^{\mathrm{a}}$ & $61 \pm 5.36^{\mathrm{a}, \mathrm{e}}$ \\
Uric acid (mg/dl) & $3.7 \pm 0.3$ & $2.05 \pm 0.21^{\mathrm{b}}$ & $1.08 \pm 0.61^{\mathrm{d}, \mathrm{h}}$ \\
SGOT (U/L) & $74.9 \pm 7.5$ & $63.35 \pm 5.16^{\mathrm{a}}$ & $3.1 \pm 0.43^{\mathrm{d}, \mathrm{f}}$ \\
SGPT (U/L) & $71.5 \pm 7.5$ & $75 \pm 8.12^{\mathrm{d}}$ & $85.91 \pm 8.75^{\mathrm{d}, \mathrm{e}}$ \\
Bilirubin total (mg/dl) & $1.06 \pm 0.01$ & $0.63 \pm 0.06^{\mathrm{c}}$ & $71.47 \pm 6.96^{\mathrm{d}, \mathrm{h}}$ \\
Alkaline phosphatase (U/L) & $130.1 \pm 15.12$ & $235.1 \pm 21.3^{\mathrm{b}}$ & $0.85 \pm 0.03^{\mathrm{c}, \mathrm{f}}$ \\
Total protein (g/dl) & $6.8 \pm 0.35$ & $5.21 \pm 0.43^{\mathrm{b}}$ & $71.47 \pm 6.96^{\mathrm{d}, \mathrm{h}}$ \\
\hline
\end{tabular}

Values expressed as mean \pm SEM ( $n=5$ ). Groups II to IV compared with Group I, where ${ }^{a} p \leq 0.05$, ${ }^{b} p \leq 0.01$, ${ }^{c} p \leq 0.001$ and dnon-significant=d. Groups III and IV are compared with Group II, where ${ }^{\mathrm{e}} \mathrm{p} \leq 0.05,{ }^{\mathrm{f}} \mathrm{p} \leq 0.01,{ }_{\mathrm{g}}^{\mathrm{g}} \mathrm{p} \leq 0.001$ and hnon-significant=h. SEM: standard error of the mean

while treatment with $70 \%$ EtOH extract of cumin seed showed a significant reduction in plaque size and restoration of arterial wall integrity. These findings were comparable to atorvastatin-treated groups.

\section{DISCUSSION}

Diet with a high level of cholesterol and fat has shown to promote the progression of atherosclerosis $[13,14]$. Major risk factors for coronary heart disease include hypercholesterolemia, hypertension, cigarette smoking, diabetes, and high cholesterol-rich and fat diet, which eventually result in impairment of endothelial function which further develops atherosclerosis $[13,15]$. It is well established that hyperlipidemia is one of the major risk factors in CVD, including atherosclerosis. Managing hyperlipidemia as a way to prevent atherosclerosis is a common activity in the treatment of this disease [16]. Current treatment therapies treat the disease either by lowering the cholesterol production through inhibition of HMG-CoA reductase enzyme in liver (like statins) or by lowering serum TG level (like fibrates) or by increasing apo-A-1 containing lipoproteins (like niacin) [17], but all these treatment drugs leave a large burden of residual untreated disease [18,19]. Excess administration of cholesterol results in the occurrence of hypercholesterolemia and atherosclerosis [20]. In the present experiment, high cholesterol diet administration caused increased concentration of serum TC, LDL-C, VLDL, and TG level. These findings were also observed in another study in which animals respond to the atherogenic diet with a significant increase in total plasma cholesterol concentration [21]. Elevated level of LDL-C, VLDL, and TG plays a vital role in plaque formation. LDL and their modified forms and serum TG have a harmful effect on the musculature of endothelium [22]. Accumulation of lipid is the first necessity for the plaque formation, lipid deposition initiates with the movement of LDL-C from the blood into the vessel wall [23], while LDL has a fundamental physiological role as a vehicle for the delivery of cholesterol, and its high concentration in bloodstream is associated with increased risk of CVD [2]. Statins are among the most prescribed class of medication used in the last couple of years. The beneficial effect of statin is due to their capacity of reducing cholesterol biosynthesis mainly in the liver, by competitively inhibiting HMG-CoA reductase enzyme $[4,24]$. Raised lipid-lowering effect of $70 \%$ EtOH extract of cumin seed was comparable to that of atorvastatin. Cumin seed has the cholesterol-lowering capacity. Administration of cumin seed caused a reduction in serum TC and also shows hypoglycemic effects, and similar findings were observed in the present study also. These findings are supported by another study in which administration of cumin seed powder capsule was reported to lower down the serum cholesterol as well as serum insulin level in diabetes Type-II suffering patients [25]. In another study, overweight patients showed a reduced level of serum TC, TG, and LDL-C [26]. Methanolic extract of cumin seed has been reported to exhibit the hypolipidemic effect in rats [27]. Besides this, the plant also has antioxidant activity with an antioxidant index of 1.3 , due to the presence of the cuminic aldehyde, p-mentha-3-en-7-al, and several flavonoids reportedly apigenin7-o-glucoside, apigenin-5-o-glucoside, and luteolin-7-o-glucoside [28]. The mechanism of action of the drug may involve inhibition of HMG-CoA reductase enzyme or by inhibition of cholesterol absorption in the small intestine or the drug may have some anti-inflammatory and antiplatelet aggregation activity which stops plaque progression.

\section{CONCLUSION}

The present study proves that the plant $C$. cyminum $\mathrm{L}$. has an antiatherosclerotic effect due to its capacity to reduce ox-LDL and LDL concentration in serum, and both the elements play a central role in developing atherosclerosis. The plant also possesses antioxidant, hypoglycemic, anticancerous, and carminative effect.

\section{ACKNOWLEDGMENT}

We would like to acknowledge Head, Department of zoology, Jai Narain Vyas University, Jodhpur, for providing all the necessary amenities.

\section{AUTHORS' CONTRIBUTIONS}

The complete research work was suggested and mentored by Prof. Ashok Purohit. All the experimental work was performed by Harshlata Chouhan. Authors drafted and approved the final manuscript.

\section{CONFLICTS OF INTEREST}

The author declares no conflict of interest. 


\section{REFERENCES}

1. Doran AC, Meller N, McNamara C. Role of smooth muscle cell in the initiation and early progression of atherosclerosis. Arterioscler Thromb Vasc Biol 2008;28:812-9.

2. Urrutia JK, Tampis RL, Mercado J, Baygan AM. Survival analysis for the risk of developing heart attack. Int J Pharm Pharm Sci 2016;8:6-10.

3. Schschter M. Chemical, pharmacokinetic and pharmacodynamic properties of statin: An update. Fundam Clin Pharmacol 2004;19:117-25.

4. Stancu C, Sima A. Statin: Mechanism of action and effects. J Cell Mol Med 2001;5:378-87.

5. Thompson P, Panza G, Zaleski A, Taylor B. Statin: Associated side effects. J Am Coll Cordiol 2016;67:5-2410.

6. Matarneh R, Sotnik S, Lyashenko V. Polymers in cardiovascular surgery. Asian J Pharm Clin Res 2018;11:58-63.

7. Al-Snafi AE. The pharmacological activities of Cuminum cyminum - A review. IOSR J Pharm 2016;6:46-65.

8. Adisakwattana S, Jeerasuk M, Srichairt S, Chanasit C, Tirapongporn H, Chanathong B, et al. Lipid lowering mechanism of grape seed extract (Vitis venifera) and its antihyperlipdemic activity. J Med Plant Res 2010;4:2013-120.

9. Tomar RS, Sharma B, Kaushik, S. Mishra RK. Potential antifungal activity of essential oils and their application in food preservation. Asian J Pharm Clin Res 2018;11:58-63.

10. Wintrobe WM. In: Greer JP, Wintrobe MM, editors. Wintrobe's Clinical Hematology. $12^{\text {th }}$ ed. USA: Lippincott Williams \& Wilkins Health; 2011. p. 121-225.

11. Friedewald WT, Levy RI, Fredrickson DS. Estimation of the concentration of low-density lipoprotein cholesterol in plasma, without use of the preparative ultracentrifuge. Clin Chem 1972;18:499-502.

12. Varley H. In: Gowenloch AH, Mcmurry JR, Mclauchlan DM, editors. Varley's Clinical Biochemistry. $6^{\text {th }}$ ed. India: CBS Publishers and Distributors Pvt. Ltd.; 2006. p. 333-452.

13. Chadha R. Purohit K. Wheat bran extract mimics statin like action in hyperlipidemic rabbits: An experimental study. Asian J Pharm Clin Res 2018;11:402-5.

14. Purohit A, Vyas KB. Antiatherosclerotic effect of Caparis deciduas. fruit extract in cholesterol fed rabbits. Pharm Biol 2006;44:172-7.

15. Purohit A, Ram H. Hypolipidemic and ant atherosclerotic effects of Prosopis cineraria. Bark extract in experimentally induced hyperlipidemic rabbits. Asian J Pharm Clin Res 2012;5:106-9.

16. Vogel VR. Coronary risk factor, endothelial function, and atherosclerosis: A review. Clin Cardiol 1997;20:426-32.

17. Nelson HR. Hyperlipidemia as a risk factor for cardiovascular disease. Prim Care 2013;40:195-211

18. Kamanna VS, Kashyap ML. Mechanism of action of niacin. Am J Cardiol 2008;101:S20-6.

19. Torgal SS, Sugato CH. Effect of metformin and simvastatin in diazepam and sodium nitrite induced anterograde amnesia in male Swiss albino mice. Int J Pharm Pharm Sci 2018;10:18-22.

20. Tall AR, Yvan-charvel L, Terasaka N, Pagler T, Wang N. HDL, ABC transporters and cholesterol efflux: Implication for the treatment of atherosclerosis. Cell Metab 2008;7:365-75.

21. Strocker R, Keaney JF Jr. Role of oxidative modification in atherosclerosis. Physiol Rev 2004;84:1381-478.

22. Badimon JJ, Badimon L, Fuster V. Regression of atherosclerotic lesions by high density lipoprotein in plasma fraction in the cholesterol-fed rabbit. J Clin Invest 1990;85:1234-41.

23. Kaperonis EA, Liapis CD, Kakisis JD, Dimitroulis D, Papavassiliou VG. Inflammation and atherosclerosis. Eur $\mathrm{J}$ Vasc Endovasc Surg 2006;36:386-93.

24. Crowther MA. Pathogenesis of atherosclerosis. Hematology Am Soc Hematol Educ Program 2005; 1:436-41.

25. Jafari S, Sattari R, Ghavamzadeh S. Evolution of 50 and $100 \mathrm{mg}$. dose of Cuminum cyminum essential oil on glycemic indices, insulin resistance and serum inflammatory factors on patients with diabetes Type-II: A double blind randomized placebo controlled clinical trial. J Tradet Complment Med 2016;7:332-8.

26. Taghizadeh M, Ostad SN, Asemi Z, Mahboubi M, Hejazi S, Chaleshtori R, et al. Sub chronic oral toxicity of Cuminum cyminum L's essential oil in female wistar rat. Iran Red Crescent Med 2016;18:e34212.

27. Shirke SS, Jagtap AJ. Effects of methanolic extract of Cuminum cyminum on total cholesterol in ovariectomized rats. Indian J Pharmacol 2009;41:91-3.

28. Ravi R, Prakash M, Bhat KK. Characterization of aroma active compounds of cumin (Cuminum cyminum) by GC-MS, E-NOSE, and sensory techniques. Int J Food Prop 2013;16:1048-58. 